\title{
Advancement and Improvement of CRM with the Use of Statistics Mining Strategies
}

\author{
Shabanaunnisa Begum
}

\begin{abstract}
Abstract consumer relationship control (CRM) is a system that mainly deals with the communication among a enterprise and its customers. CRM thru facts mining can get more efficiency in obtaining new customers, increasing fee of present clients and preserving excellent clients. The number one users of CRM software program programs are database entrepreneurs who are seeking to automate the system of interacting with clients. To achieve success, database marketers ought to first become aware of marketplace segments containing clients or prospects really worth high-income ability. Statistics mining technology are relevant in lots of methods models and strategies which are used to go looking variety of patterns and relationships of different forms of facts. Statistics mining applications system of looking within the automation gear which reaches to the mountains of facts to look patterns that are good predictors of buying behaviors.After information mining, marketers need to display the outcomes into which coping with the enterprise market described in immediately way.
\end{abstract}

Key Words: Customer Relationship Management, Data items, K-means .

\section{INTRODUCTION}

\section{1) 1.1 Customer Relationship Management}

CRM is a philosophy of business operation for acquiring and keeping clients, growing purchaser price, loyalty and retention, and imposing customer-centric techniques. CRM, devoted to improve relationships with purchaser, makes a speciality of a complete photograph on a way to integrate patron value, necessities, expectancies and behaviors via analyzing facts from transaction of consumer . Organisations can shorten income cycle and increase customer loyalty to build higher near relationships with clients and similarly upload sales by using correct CRM. Consequently, an splendid CRM can assist organizations retaining current customers and attracting new ones.

The commercial employer strategies and era answers round selling, advertising and marketing, and servicing capabilities throughout all purchaser contact-factors (for example: net, email, cell phone, fax, in-person)". The main goal of CRM applications is to attract, retain and control a firm's profitable ("right") clients. Digital calculation for such things is furnished through the firm's commercial enterprise intelligence machine. Enterprises apply some methods to effectively enhance customer relationships, which include customer relationship management, customer value analysis, enterprise strategy, and positive service mechanisms. Moreover, enterprises also strengthen

Revised Manuscript Received on 14 August, 2019. Dept

Shabanaunnisa Begum, MRECW, Maisammaguda, Asst Professor ,Cse

marketing and sales effectiveness in order to build good CRM. Kalakota and Robinson (1999) explained that the CRM is to integrate the function of the related fields with customer in the enterprise such as marketing, sales, services and technical support for customer needs, and it usually utilizes IT to help an enterprise managing relationships with customer in a systematic way, improving customer loyalty and increasing overall business profits. It has been estimated that it costs five times as much to attract a new customer as it does to retain a existing one, according to research by the American management Association and this relationship is particularly obvious in the services sector. Therefore, enterprises understand the importance of developing a good close relationship with existing and new customers. Instead of attracting new customers, they would like to perform possible more business operations for customers in order to keep existing customers and build up long term customer relationship. Based on this reason, this study ensures that enterprises should be implementing customer data analysis to understand about their customers, to retain valuable customers and finally to bring plenty profits for themselves.

CRM refers to the approach in which all of the technology are adopted with the assist of firms to sophisticate their relationships with customers. Statistics accumulated on cutting- facet customers (and prospective clients) is evaluated and used for the cargo. Computerized consumer relationship control techniques are often used to create automated custom designed marketing based on client information from the tool. CRM is the employer-level statergy, concentrated on to make correct relationships with clients. Numerous organisation CRM software program answers have special approach to CRM, on the other hand, CRM isn't always a generation, but pretty a holistic approach to an company's factor of view, having the significance on the patron resolutely. CRM direct an enterprise's viewpoint at all stages, collectively with pointers and tactics, customer service, personnel schooling, systems and records manage, marketing. CRM solutions have integrated non-stop advertising, income and consumer services. A CRM machine should classify elements to clients, propose a purchaser-oriented technique, receive purchaser based measures, provide higher customer support, and extend lower back-to-lower back procedures for customers/clients.

\section{RESEARCH MODEL}

The study constructs a model for yielding input attributes by attribute reduction through RS theory, the reduced attributes are passed to UCAM clustering and membership of each customer is obtained through Fuzzy-UCAM clustering.

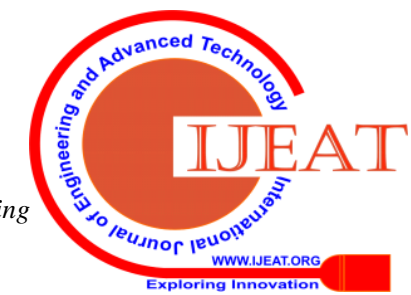




\section{Advancement And Improvement Of CRM With The Use Of Statistics Mining Strategies}

This research model is the enhancement of data mining process by including UCAM, Fuzzy-UCAM and RF-UCAM is as listed below

- Problem Definition and Data acquisition

- Data Pre-processing and survey

- Feature reduction via RF-UCAM

- Clustering via UCAM and Fuzzy - UCAM

- Data Modeling

- Evaluation

- Knowledge deployment

Enhancing RF-UCAM with facts mining allows to have reduction on attribute set which reduces the computational complexity. UCAM clustering set of rules is used for obtaining precise cluster and where as Fuzzy-UCAM is facilitates to get fuzzy membership matrix for the objects inside the cluster. This segment in short introduces the research version of this have a look at and the proposed procedure for segmenting consumer. CRM is to acquire the desires of customers and beautify the power with clients for business enterprise. In latest years, records mining has first-rate popularity in studies vicinity however no tool for statistics mining in CRM is perfect because there are some unsure draw- backs in it together with clustering has earlier fixation of wide variety of clusters and seeds, in choice bushes, too many times lower classification accuracy fee, and so forth. To clear up the hassle above, 3 strategies, rough set theory, okay-way set of rules and Fuzzy C-way are really worth to be provided in this have a look at. This examine proposes a new procedure, joining RS concept; more desirable k-approach (UCAM) and enhanced Fuzzy C-manner (Fuzzy-UCAM) improve those drawbacks above. This procedural technique gives get up to an algorithm RF-UCAM, which is printed beneath

Input: $\mathrm{D}=\left\{\mathrm{t}_{1}, \mathrm{t}_{2}, \mathrm{t}_{3} \ldots \mathrm{t}_{\mathrm{n}}\right\} / /$ Set of $\mathrm{n}$ data points.

$\mathrm{T}$ - Threshold value.

Output: Clusters. Number of cluster depends on affinity measure.

Method:

Set the threshold value $\mathrm{T}$

Discretize continuous attributes to enhance through sets algorithm. Rough set attribute reduction is carried out for dimensionality reduction.

\section{SYSTEM APPROACH \\ 3.1 Merging CRM and Data Mining technologies \\ 3.1.1 Creation of customer database}

A first step is important to complete CRM answer that is construction of client/stop consumer database. This will be the idea of any CRM interest. In the commercial enterprise which are web-primarily based it's miles tremendously truthful pastime because the purchaser transactions and the purchaser information are gathered as a first-rate part of conversation with customers. The organizations which can be running in this unique area they are 3 gathering facts about customers. This undertaking consists of getting historical consumer information from their inner resources. The query is : What to be extracted from the existing facts?
Essentially database consists of large facts which incorporate following facts:

1. Transaction/hobby: continues tracks of the purchaser hobby.

2. Purchaser info: Now-a-days clients are available from many categories, so that you could its miles essential to have maximum of the data approximately purchaser/quit user.

3. Patron connections: purchaser contacts and the referencing to the opposite customers supply a lift to the commercial enterprise because it does not require organization interference.

\section{2) 3.1.2 Data Analysis}

Traditionally, the database of clients is analyzed with the purpose to define and segregate the customers segments. Numerous multivariate statistical strategies which includes cluster and discriminate analysis were used to make a community of a community of customers with comparable behavioral patterns and descriptive information which then applied to develop different product imparting or a direct advertising and marketing campaign. In general direct entrepreneurs make use of such strategies for plenty past years. Their intention is to goal the maximum most appropriate prospects for catalogue mailings to conform the catalogue appropriate for one-of-a-kind customers.

\section{3) 3.1.3 Selection of Customers}

"The method of purchaser elimination is likewise termed as purchaser selection" which has big significance in CRM strategies. As CRM is a basically customer oriented enterprise method and subsequently we pays interest to improve responsiveness to the adjustments in purchaser necessities. Serving all clients may not be vital as among the clients are occasional users, for this reason the companies running over this. Traditionally, the database of customers are analyzed with the purpose to define and segregate the customers segments. Various multivariate statistical methods such as cluster and discriminant analysis have been used to make a community of a community of customers with similar behavioral patterns and descriptive data which then utilized to develop different product offering or a direct marketing campaign. Mostly direct marketers utilize such techniques for many past years. Their aim is to target the most preferable prospects for catalogue making to adapt the catalogue suitable for different customers.

\section{4) 3.1.4 Selection of Customers}

"The method of consumer removal is likewise termed as consumer choice" which has big significance in CRM strategies. As CRM is a simply client orientated enterprise method and hence we can pay interest to enhance responsiveness to the changes in purchaser requirements. Serving all clients might not be essential as some of the clients are occasional customers, consequently the agencies working over this approach will have to don't forget set of client to reduce time and also workload. In order that business could develop successfully. The 
end result from the evaluation section will be of various kinds. Purchaser contributing the following categories are commonly decided on first for the similarly manner (e.G., highest shopping quotes, more brand loyalty and many others). If person patron-based totally profitability is to be had thru LCV manner or any similar analysis the determination of customer selection will become less complicated technique. Advertising supervisor is accountable to make numerous type of analysis to focus a selected clients. The intention is to make use of consumer profitability, for you to provide long time guarantee of the earnings to company. Those clients also gives facts to the supervisor to hearth the patron that is pricey to serve relative to that of the sales produced through them.

\section{5) 3.1.5 Focusing the Customers}

Conventional methods such of mass advertising like television, radio, or print media and marketing are beneficial in growing awareness and achieving other verbal exchange targets, but in latest international they're taken into consideration as slow communication channel hence, they're poorly appropriate for the CRM machine due to their unbiased nature. The ordinary approaches for concentrated on decided on customers include direct marketing methods like telemarketing, mail, direct messages. When the character of product is suitable direct sales strategy is also desired. Because of the net the new strategy is followed through the companies to paintings in a 1-to-1 advertising with clients. Customized E-mails are the maximum favored way in direct advertising and marketing.

\section{6) 3.1.6 Relationship Packages}

While customer contact thru direct email services is a beneficial element of CRM. Relationships are not constructed and sustained with direct electronic mails themselves however instead thru the types of programs that are available for which e mail can be a conversation mechanism. The overall aim of relationship packages is to deliver a better level of customer satisfaction. Managers these days feel that clients in shape Realizations and expectations of product general overall performance, and that it is critical for them to supply such overall performance at higher and better levels as expectations increase due to immoderate or heightened competition, and changing client desires. Similarly, research has proven that there may be a strong, great relationship among customer pleasure and earnings. Managers need to constantly degree delight stages and increase applications that help to deliver overall performance past focused client expectations

\section{7) 3.1.7 Confidentiality}

The ones CRM framework characterized depends upon An database about customer records and evaluation of the facts for all of the greater succesful and focused on promoting furthermore marketing interchanges also dating-constructing physical games. There is probably a evident tradeoff "around the ones capability of associations have to finer convey custom planned items furthermore administrations and the amount of facts necessary with tolerance this transport. Uncommonly with the Ubiquity of the internet, A large variety customers what is more backing aggregations need resource involved across the degree approximately specific facts held carried out databases what's extra entryway it can be getting applied.

\section{8) 3.1.8 Metrics}

9) The extended hobby paid to CRM method that the traditional metrics used by managers to diploma the fulfillment in their products and services within the marketplace want to be up to date. Financial and market-based definitely signs like profitability, marketplace share, and earnings margins were and will stay critical. However, in a CRM global, prolonged emphasis is being placed on growing measures which are client-centric and supply the supervisor a higher idea of the manner the CRM rules and programs are working.

\subsection{Customer Retention Program \\ 10) 3.2.1 Customer Service}

As because clients have more picks nowadays and the focused clients are most treasured to the organisation, customer support should receive a high priority inside the agency. packages designed to beautify customer support are usually of two types. Reactive service is where the purchaser has a trouble (product failure, question about a invoice, product return) and contacts the organization to clear up it. most agencies these days have hooked up infrastructures to address reactive service conditions. Proactive service is a distinct count; that is a situation where the manager has decided now not to await customers to touch the firm however to alternatively be competitive in organising a communicate with clients revious to complaining or other conduct sparking a reactive solution.

\subsubsection{Loyalty/Frequency programs}

Loyalty applications (also known as frequency packages) provide rewards to customers for repeat shopping. a number of internet-primarily based companies providing incentives for repeat visits to net websites. even though these have not been wildly a success, it's far clean that the rate orientation of many net customers creates the need for applications that could generate loyal conduct.

\section{1) 3.2.3 Customization}

The concept approximately impostor customization may be placing off secret word 1-to-1 selling also showcasing as a result it infers those prologue about outcomes furthermore administrations for mamoncillo or woman clients, by no means once more without a doubt speaking to them. Customization is called "versioning." it is, from claiming direction, less complicated must try this to administrations also immaterial protecting detail merchandise over for inventory but the illustrations over suggest that significantly manufacturers camwood make get of the advanced Realities handy beginning with clients must tailor inventory that during any event bring those presence for continuously custom outlined regardless of they could make without a doubt editions beforehand a as a relatable point construct.

\section{2) .4 Reward programs}

Numerous corporations used to give rewards to its customers on successive shopping for in their objects. Reward may be a present item or cash returned or like good deal coupon, which

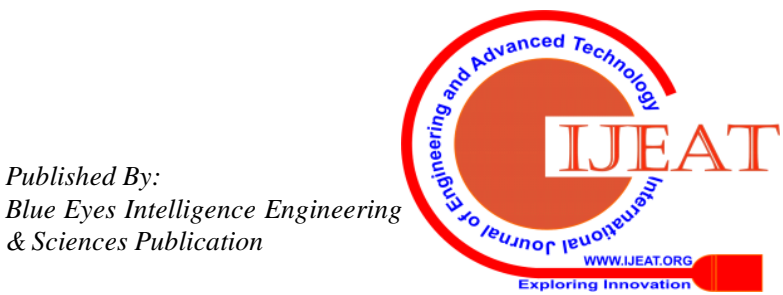


may be achieved on buying the next item from the equal agency.

\section{3) 3.2.5 Community Building}

One of the principal uses of the internet for each on line and offline corporations is to construct a network of customers for exchanging product-associated facts and to create relationships among the clients and the agency or emblem. These networks and relationships are called communities. The goal is to take a potential relationship with a product and flip it into something extra non-public. In this way, the supervisor can build an environment that makes it more difficult for the purchaser to depart the "own family" of various folks that also purchase from the organization.

\section{SYSTEM IMPLEMENTATION}

\section{K-means clustering Algorithm}

$\mathrm{K}$-means is signal processing originated method of vector quantization, which is a famous method for cluster analysis in data mining. This algorithm aims to partition $n$ observations into $\mathrm{k}$ clusters which every observation belongs to the cluster with the nearest mean. This process makes the partitioning of the data space into Voronoi cells. There are heuristic algorithms that are commonly used and combined quickly to find a local optimum. K-means clustering finds clusters of comparable spatial extent.

Description:-

Given: Set of observations $\rightarrow\left(X_{1}, X_{2}, \ldots, X_{n}\right)$.

Aim: To partition the no of observations into k clusters $(\mathrm{k} \rightarrow$ no.of clusters). [Note: $\mathrm{k}<=\mathrm{n}$ ]

The technique also minimizes the within cluster sum of square also known as variance.

Output: sets $S=\left(S_{1}, S_{2}, \ldots, S_{n}\right)$.

\section{Algorithm:-}

Input: no. of clusters $\rightarrow \mathrm{k}$ set of dimensions $\rightarrow \mathrm{D}$

Output: set of $\mathrm{k}$ clusters Procedure:

Randomly choose $\mathrm{k}$ dimensions from $\mathrm{D}$ as initial cluster centers;

\section{4) Repeat:}

1. (Re)assign each object to the cluster to which the object is the most similar, based on the mean value of the objects in the cluster;

2. Update the cluster means, i.e. calculate the mean value of the objects of each cluster Until no change;

\section{TECHNICAL APPROACH}

At the time of insertion of the goods inside the shopping cart we assign a particular code for a class/area. Then those categories additionally incorporate category according to the brand. The actual product identity consists of following special fields (category_id, brand_id, product_id). Now, from the patron surfing history by means of taking client action in consideration we make a customer database, which continues the statistics and the statistics approximately the customer hobby. After mining database we get brief idea about the purchaser necessities and the hobby of client. After the mining technique automatic email generation module takes the manage and sends the mail to the customer. In this way the consumer dating is maintained using technology. It makes the technique very simple and efficient. Also reduces paperwork and enables to preserve the surroundings. The gadget reduces the human intervention, hence there gained't be any risk of human blunders. The device gives the exact outcomes, hence it facilitates to boosts the income of the marketers.

\section{B. 6. REQUIREMENTS}

Hardware Requirement
\begin{tabular}{|l|l|}
\hline Hardware & Specification \\
\hline Processor & Intel core 2 duo or above \\
\hline RAM & $2 \mathrm{~GB}$ \\
\hline
\end{tabular}

Software Requirement

\begin{tabular}{|l|l|}
\hline Software & Specification \\
\hline $\begin{array}{l}\text { Operating } \\
\text { System }\end{array}$ & $\begin{array}{l}\text { Microsoft Windows 7/8/10 } \\
\text { or Unix }\end{array}$ \\
\hline Platform & Xampp/lampp server \\
\hline
\end{tabular}

\section{V.CONCLUSION}

Nowadays, the e-commerce and e-marketing is very important concept as the whole market has been controlled by using internet technologies. To maintain a healthy relationship with customers and end users the e-commerce comprises a lot. Such types of tools and technologies are been used by e-commerce companies. This leads to increase the profit and business also.

\section{REFERENCES}

1. J.Han and M. Kamber, Data Mining: Concepts and Techniques (2nd ed.). Morgan Kaufmann, 2006.

2. The inventory management for retailer with mental accounting under stock-dependent demand", 2015.

3. Parvatiyar, A., \&amp; Sheth, J. N. "Customer relationship management: Emerging practice, process, and discipline", Journal of Economic \&amp; Social Research, 2001,3, 1-34.

4. Shu-hsien Liao, Yin-ju Chen, Hsin-hua Hsieh,"Mining customer knowledge for direct selling and marketing “, Expert Systems with Applications, 2011, 38, 6059-6069.

5. Han, J. and Kamber, M. (2006) Data Mining Concepts and Techniques. Morgan Kaufmann Publisher, Burlington, MA: Elsevier.

6. Larose, D.T. (2005) Discovering Knowledge in Data. New Jersey: John Wiley \& Sons.

7. Mitra, S., Pal, S.K. and Mitra, P. (2002) Data mining in soft computing framework: A survey. IEEE Transactions on Neural Networks 13(1): $3-14$.

8. Ngai, E.W.T., Hu, Y., Chen, Y. and Sun, X. (2011) The application of data mining techniques in financial fraud detection: A classification framework and an academic review of literature. Decision Support Systems 50(3): 559-569 